\title{
Complex Sympathetic Regulation in Adolescent Mitral Valve Prolapse
}

\author{
Lucia BONA OLEXOVA ${ }^{1,2}$, Zuzana VISNOVCOVA ${ }^{2,1}$, Nikola FERENCOVA ${ }^{1,2}$, Alexander \\ JURKO Jr. ${ }^{3}$, Ingrid TONHAJZEROVA ${ }^{1,2}$
}

${ }^{1}$ Department of Physiology, Jessenius Faculty of Medicine in Martin, Comenius University in Bratislava, Martin, Slovak Republic, ${ }^{2}$ Biomedical Centre Martin, Jessenius Faculty of Medicine in Martin, Comenius University in Bratislava, Martin, Slovak Republic, ${ }^{3}$ Pediatric Cardiology, Jessenius Faculty of Medicine in Martin, Comenius University in Bratislava, Martin, Slovak Republic

Received March 16, 2021

Accepted October 26, 2021

\begin{abstract}
Summary
Mitral valve prolapse (MVP) belongs to cardiac disorders characterized by impaired closure of mitral leaflets. We studied adolescent group of patients with MVP suffering from symptomatology that cannot be explained by mitral regurgitation alone. Several studies suggested that symptoms can be explained by autonomic, in particular sympathetic-linked dysfunction. Thus, we assessed non-invasive sympathetic indices of blood pressure and heart rate variability and electrodermal activity (EDA). Fifty-three adolescents with MVP (age: $15.1 \pm 0.4$ years) and 43 healthy age- and gender-matched adolescents (age: 14.9 \pm 0.4 years) were examined. Blood pressure, heart rate and EDA were continuously recorded during 6-min rest. Evaluated parameters were: low frequency band of systolic blood pressure variability, systolic, diastolic and mean blood pressure, mean RR interval, cardiac sympathetic indices: symbolic dynamics (OV\%), left ventricular ejection time (LVET), pre-ejection period (PEP), and EDA. Our findings revealed significantly higher systolic, diastolic, and mean blood pressure values, shortened mean RR interval, increased $0 \mathrm{~V} \%$, and shortened LVET in MVP patients vs. controls $(p=0.028, p<0.001$, $\mathrm{p}=0.002, p<0.001, \mathrm{p}=0.050, \mathrm{p}<0.001$; respectively). Our study revealed enhanced cardiovascular sympathetic regulation in adolescent MVP patients. We suggest that evaluation of noninvasive sympathetic parameters could represent potential biomarkers for early diagnosis of cardiovascular complications associated with MVP already at adolescent age
\end{abstract}

\section{Key words}

Mitral valve prolapse • Autonomic nervous system • Sympathetic activity • Blood pressure • Adolescent age

\section{Corresponding author}

I. Tonhajzerova, Department of Physiology and Biomedical Centre Martin, Jessenius Faculty of Medicine in Martin, Comenius University in Bratislava, Mala Hora 4C, 036 01, Martin, Slovak Republic. E-mail: ingrid.tonhajzerova@uniba.sk

\section{Introduction}

Mitral valve prolapse (MVP) represents a disorder of closure of one or both mitral leaflets, what makes them billowing into the left atrium during cardiac cycle (systole) with or without regurgitation. The key issue for this diagnosis represents floppy mitral valve (FMV). This pathological/surgical term "floppy" is defined by intrinsic morphological changes resulting in the bulging of the mitral valve leaflets out of the mitral valve area, with elongated chordae tendineae, frequently associated with a dilated mitral annulus (Boudoulas et al. 2020). The common classification represents primary (idiopathic) or secondary (MVP is developed on the background of various diseases, such as figcarditis, cardiomyopathies, Marfan's syndrome, etc.) MVP (Shah 2010). Based on the background of symptomatology, patients with FMV/MVP can be divided into two basic groups. First group involves patients whose symptoms are directly related to progressive mitral regurgitation and its complications. In the second group are patients whose symptoms cannot be associated only with the degree of regurgitation, but may be result of neuroendocrine or autonomic dysfunction referred as the FMV/MVP syndrome (Boudoulas et al. 2016). At present, little 
attention is given to autonomic dysregulation associated with this diagnosis.

FMV/MVP syndrome includes symptoms like palpitations, orthostatic rhythm disorder, exertional dyspnea, anomalous chest pain, syncope, and neuropsychiatric symptoms (e.g. anxiety) (Shah et al. 2020). It has been proven that these symptoms cannot be explained by mitral valve abnormalities and regurgitation alone. Besides, in certain patients were symptoms present many years prior the significant mitral valve regurgitation (Boudoulas and Boudoulas 2013, Theofilogiannakos et al. 2015). Recent studies reported that reasons causing symptoms could be explained by functional abnormalities of the autonomic nervous system (ANS) or neuroendocrine dysfunction in patients with FMV/MVP syndrome (Miller et al. 2018, Boudoulas et al. 2020). Previous studies reported sympathetic overactivity and decreased vagal tone, which is probably associated with the origin and pathogenesis of MVP (Chang et al. 2016, Bilovol et al. 2019).

Heart rate variability (HRV) represents a promising tool for assessment of ANS regulatory dynamics (Shaffer and Ginsberg 2017). With respect to parasympathetic activity, Chang et al. (2016) reported decreased vagal activity in MVP patients. Moreover, our previous study in this field revealed impaired cardiovagal control indexed by short-term HRV in adolescents with MVP (Bona Olexova et al. 2020). In contrast, the evaluation of sympathetic activity from short-term HRV linear analysis is controversial (Goldstein et al. 2011). In this context, the nonlinear HRV analysis - symbolic dynamics is assumed to be better than conventional spectral indices regarding its sensitivity to sympathetically mediated heart rate fluctuations (Porta et al. 2007, Visnovcova et al. 2014). Due to the latest studies, symbolic dynamics $0 \mathrm{~V} \%$ index represents a noninvasive marker of cardiac sympathetic regulation independent on myocardial preload and afterload influencing frequently used pre-ejection period (PEP) (Mestanik et al. 2015, Silva et al. 2017). Further, sympathetic cardiac control could be indexed by wellestablished parameter PEP, which provides information about beta-adrenergic influences on the myocardium (Berntson et al. 2016, Garrido et al. 2020). Moreover, left ventricular ejection time (LVET) represents index of sympathetic chronotropic effects through the actions of the sinoatrial node (Hill et al. 2010). Additionally, $\mathrm{PEP} / \mathrm{LVET}$ ratio is considered as the single most useful measurement of left ventricular dysfunction when either or both the PEP and LVET are in normal range (Tavakolian 2016, Corîci et al. 2018).

For complex assessment of sympathetic control, vascular sympathetic modulation may be expressed by spectral analysis in the low-frequency range of the systolic blood pressure variability (LF-SBPV) reflecting thus alpha-adrenergic vascular tone (Mestanik et al. 2015, Grilletti et al. 2018). Additionally, it has been proven that short-term blood pressure variability (BPV) is comparable with long-term BPV monitoring (Jíra et al. 2010). With respect to other sympathetically mediated effectors, electrodermal activity (EDA) is a non-invasive index of sympathetic cholinergic activity. Specifically, the skin's ability to conduct electricity is related to activity of eccrine sweat glands, which reflects changes of sympathetic activity (Dawson et al. 2000, Figner and Murphy 2010). Thus, dynamic variations of the sympathetic activity estimated by EDA represents an important prognostic and diagnostic marker in autonomic dysfunction-linked diseases (Posada-Quintero et al. 2016).

Sympathetic activity has not been evaluated in such a comprehensive view in the MVP yet. Therefore, we aimed to study complex sympathetic regulation using BPV, HRV, and EDA analysis in adolescent patients with primary MVP. To the best of our knowledge, it is the first study to assess sympathetic regulation of different effectors' responses in adolescent MVP.

\section{Methods}

The study was approved by the Ethics Committee of Jessenius Faculty of Medicine in Martin, Comenius University in Bratislava in accordance with the 1964 Helsinki declaration and its later amendments. All subjects and their parents were carefully instructed about the study protocol and they gave informed written consent to participation in the study prior to the examination.

\section{Subjects}

We examined 53 adolescents with MVP (40 girls, 13 boys, age: $15.1 \pm 0.4$ years, body mass index: $18.5 \pm 0.3 \mathrm{~kg} / \mathrm{m}^{2}$ ) and age/gender-matched 43 healthy adolescents as control group (31 girls, 12 boys, age: $14.9 \pm 0.4$ years, body mass index: $20.3 \pm 0.4 \mathrm{~kg} / \mathrm{m}^{2}$ ). The subjects with MVP were recruited from specialized Pediatric Cardiology, external workplace of Jessenius Faculty of Medicine in Martin. The diagnosis of MVP was determined by specialist in pediatric 
cardiology. MVP was suspected according to the presence of typical midsystolic click during auscultation which occurred alone or coupled with telesystolic murmur. All patients were characterized by symptoms of palpitations, syncope, chest pain or fatigue. Additionally, non-specific changes were presented on ECG recordings, e.g. flat or inverted T waves in II, III and aVF leads. The diagnosis of MVP was definitely confirmed by crosssectional echocardiography, showing prolapse of one or both mitral leaflets in the long-axis view and fourchamber view. Moreover, mitral regurgitation was revealed in all patients with MVP by Doppler echocardiography. The exclusion criteria for both (MVP and control) groups were following: smoking, overweight and obesity, history of recent acute illness or respiratory, endocrinological, neurological, metabolic, or infectious diseases or mental disorders. Only participants without pharmacological treatment were enrolled in the study.

\section{Study protocol}

The examinations were performed in the psychophysiological laboratory (Biomedical Centre Martin, Jessenius Faculty of Medicine in Martin) under standard conditions (quiet room, temperature: $22-23{ }^{\circ} \mathrm{C}$, humidity: $45-55 \%$ ), with the minimalization of stimuli, in the morning hours between 8:00 and 12:00 a.m., after normal breakfast. The participants were instructed to avoid physical exercise at least $24 \mathrm{~h}$ prior the examination.

Firstly, anthropometric parameters were assessed by body composition analyser InBody 120 (Biospace Co. Ltd, Seoul, Korea). Afterwards, participants were asked to sit comfortably in a special armchair and rest for $10 \mathrm{~min}$ to avoid a potential effect of stress. Consequently, sensors for continuous recordings of the heart rate (HR), blood pressure, and EDA biosignals were applied with instruction to remain in sitting position for a $6 \mathrm{~min}$ at rest.

\section{HRV nonlinear analysis - symbolic dynamics}

Time series of RR intervals derived from HR were performed using Polar V800 (Polar Electro, Kempele, Finland) with sampling frequency $1000 \mathrm{~Hz}$. Before analysis, the data were carefully checked for the occurrence of artefacts and $5 \mathrm{~min}$ sequences without artefacts were analyzed.

The basis of symbolic dynamics is the coarsegraining of data into symbols with certain given numbers $(0,1,2,3,4,5)$ to classify the changes in the dynamics of time series. Subsequently, the symbols are divided into patterns with length $\mathrm{L}=3$. The patterns are grouped into 4 entities according to the types of numbers variations from one symbol to another (Porta et al. 2007). Three equal patterns $(0 \mathrm{~V} \%$, symbols without variations) represent a potentially sensitive index of complexity in betaadrenergic sympathetic cardiac control (Porta et al. 2007, Visnovcova et al. 2014, Mestanik et al. 2015). In addition, the length of mean RR interval (ms) was calculated.

\section{Blood pressure variability}

Beat-to-beat blood pressure (BP) with sampling rate $200 \mathrm{~Hz}$ (Finometer MIDI Model II, Finapres Medical System, Amsterdam, the Netherlands) was monitored. Waveforms of reconstructed brachial artery pressure were used with the correction of the finger cuff pressure to the heart level via built-in height correction system. The recordings were processed using Beat-Scope Easy software (Finapres Medical System, Netherlands). Before analysis, beat-to-beat series of systolic BP were carefully checked for artefacts and subsequently artefact-free segments were resampled using cubic spline interpolation with the frequency $2 \mathrm{~Hz}$. The lnLF-SBPV parameter contains cadence oscillations of systolic BP in the frequency range from 0.075 to $0.15 \mathrm{~Hz}$, i.e. Mayer waves (Stauss 2007). The lnLF-SBPV index could reflect a potential marker of sympathetic vascular regulation (Zhang et al. 2002). In addition, the systolic, diastolic, and mean blood pressures (SBP, DBP, MBP, respectively) were assessed.

\section{Systolic time intervals}

The left ventricular ejection time (LVET) (ms) as the duration of the left ventricle to eject blood corresponding to the opening and closing of the aortic valve was assessed by BeatScope easy software (Finapres medical systems, Netherlands). Pre-ejection period (PEP) (ms) as the time interval between initial ventricular depolarization and opening of the aortic valve was determined by VaSera device (Fukuda Denshi Co., Ltd. Tokyo, Japan). Moreover, the PEP/LVET ratio is considered as the most effective measurement of the left ventricular dysfunction when either or both the PEP and LVET are in the normal range (norm is from 0.30 to 0.38 ) (Tavakolian 2016, Corîci et al. 2018).

\section{Electrodermal activity}

Electrodermal activity with sampling frequency $256 \mathrm{~Hz}$ (FlexComp Biofeedback Infinity, Though Technology, Canada) was continuously recorded. Before analysis, the data were carefully checked for the occurrence of artefacts. Index SCL (skin conductance level) was calculated as a mean amplitude of tonic EDA. SCL describes quantitative changes in cholinergic 
sympathetic control. Normal values range from 0 to $30 \mu \mathrm{S}$ depending on the size of used electrodes (Venables et al. 1980, Dawson et al. 2007).

\section{Statistical analysis}

Statistical analysis was performed by SYSTAT (SSI, Richmond, USA). The Shapiro-Wilk normality statistical test was used for evaluation data distributions (Gaussian/non-Gaussian). The Mann-Whitney test was used for between-group comparison of BPV, HRV, and EDA indices because data were not normally distributed. A value of $p \leq 0.05$ was considered as statistically significant. BPV, HRV, and EDA parameters were expressed as median (interquartile range).

\section{Results}

The characteristics of both groups (MVP and controls) are summarized in Table 1. The mean RR interval was significantly shortened indicating tachycardia in the MVP group compared to controls $(p<0.001)$. MVP patients showed significantly higher SBP, DBP, and MBP compared to controls $(\mathrm{p}=0.028, \mathrm{p}<0.001$, $\mathrm{p}=0.002$; respectively). Moreover, cardiac sympathetic indices - LVET was significantly shortened and 0V\% was significantly higher in MVP group compared to controls $(\mathrm{p}<0.001, \quad \mathrm{p}=0.050 ;$ respectively). No significant differences in remaining parameters were found between groups. Results are summarized in Table 2.

Table 1. Anthropometric characteristics of groups.

\begin{tabular}{lccc}
\hline & Mitral valve prolapse & Controls & p value \\
\hline Age (years) & $15.00(12.75,17.00)$ & $15.00(13.00,17.00)$ & 0.916 \\
Weight $(\mathrm{kg})$ & $50.00(45.75,57.85)$ & $55.20(55.10,63.60)$ & 0.019 \\
Height $(\mathrm{cm})$ & $167.00(159.38,173.75)$ & $166.00(162.00,172.00)$ & 0.910 \\
BMI $\left(\mathrm{kg} / \mathrm{m}^{2}\right)$ & $18.22(17.14,19.74)$ & $20.02(18.18,21.92)$ & 0.001 \\
BSA $\left(\mathrm{m}^{2}\right)$ & $1.53(1.44,1.66)$ & $1.60(1.50,1.76)$ & 0.070 \\
\hline
\end{tabular}

Values are expressed as median (interquartile range). BMI - body mass index, BSA - body surface area. Probabilities $p \leq 0.05$ were considered to be significant.

Table 2. Parameters of blood pressure variability, heart rate variability, systolic time intervals, and electrodermal activity.

\begin{tabular}{lccc}
\hline & Mitral valve prolapse & Controls & p value \\
\hline BPV parameters & & & 0.028 \\
SBP $(\mathrm{mm} \mathrm{Hg})$ & $115.50(104.58,125.85)$ & $108.33(101.03,117.45)$ & $<0.001$ \\
DBP $(\mathrm{mm} \mathrm{Hg})$ & $72.43(66.69,79.40)$ & $64.89(61.19,70.01)$ & 0.002 \\
MBP $(\mathrm{mm} \mathrm{Hg})$ & $91.29(83.32,97.39)$ & $82.57(78.68,89.01)$ & 0.060 \\
lnLF_SBPV $\left(\mathrm{mm} \mathrm{Hg}^{2}\right)$ & $7.20(7.02,7.30)$ & $7.05(6.88,7.30)$ & $<0.001$ \\
HRV parameters & & & 0.050 \\
Mean RR interval $(\mathrm{ms})$ & $657.00(586.00,708.00)$ & $747.00(703.00,817.00)$ & $<0.001$ \\
OV\% & $40.65(29.45,54.36)$ & $33.72(21.36,44.50)$ & 0.687 \\
Systolic time intervals & & & 0.379 \\
LVET $($ ms $)$ & $268.62(257.38,281.60)$ & $289.49(278.64,296.71)$ & 0.110 \\
PEP $($ ms $)$ & $86.00(70.00,100.00)$ & $82.00(75.25,98.75)$ & $0.29(0.26,0.36)$ \\
PEP $/$ LVET $($ ms $)$ & $0.31(0.26,0.37)$ & & $1.14(0.59,3.05)$ \\
EDA parameter & $1.67(0.87,3.24)$ & & \\
SCL $(\mu S)$ & & & \\
\hline
\end{tabular}

Values are expressed as median (interquartile range). BPV - blood pressure variability, HRV - heart rate variability, EDA - electrodermal activity, SBP - systolic blood pressure, DBP - diastolic blood pressure, MBP - mean blood pressure, LVET - left ventricular ejection time, InLF_SBPV - spectral power of systolic blood pressure variability in low-frequency band, OV\% - index of the nonlinear method of HRV analysis-symbolic dynamics, PEP - pre-ejection period, SCL - skin conductance level. Probabilities $\mathrm{p} \leq 0.05$ were considered to be significant. 


\section{Discussion}

We investigated for the first time complex sympathetic activity using HRV, BPV, and EDA parameters characterizing diversity of peripheral effectors in mitral valve prolapse. The results can be summarized as follow: (1) higher complex sympathetic cardiac control ( $\uparrow 0 \mathrm{~V} \%$, shortened LVET) associated with tachycardia (shortened mean RR interval) in MVP group, (2) higher systolic, diastolic, and mean blood pressure associated with a tendency towards increasing to sympathetic vasomotor activity ( $\left.\uparrow l n L F \_S B P\right)$ in MVP group compared to controls. These findings revealed cardiovascular-linked sympathetic overactivity in adolescents suffering from MVP. Several mechanisms are suggested.

The higher cardiac-linked sympathetic activity in MVP is in agreement with recent study revealing prevalence of sympathetic activity by twice exceeded mode amplitude in MVP compared to controls (Bilovol et al. 2019). Moreover, our finding of isolated shortened LVET without change of PEP points to increased chronotropy associated with higher cardiovascular risk in MVP due to the fact that LVET represents an independent predictor of cardiovascular morbidity (Biering-Sørensen et al. 2018). Additionally, we can assume that left ventricle functioning is not altered in adolescent MVP yet, because ratio PEP/LVET has proven to be accurate measurement of left ventricle dysfunction (Corîci et al. 2018). With respect to sympathetic vasomotor activity, our findings of increased alpha-adrenergic vascular modulation are in contrast with some other studies revealing no differences in BP, or even lower SBP and DBP during 24-BP monitoring in MVP vs. controls (da Silva et al. 2007, Delling et al. 2014). Thus, we suggest higher resting cardiovascular autonomic control that can be associated with increased cardiovascular complications in MVP already at adolescent age.

From neurophysiological aspect, the autonomic regulation of the effector organs is performed through numerous structures at all levels of the central nervous system (CNS) forming interconnected complex called central autonomic network (CAN) (Benarroch 1993). Structurally, the cardiovascular areas of the brainstem (i.e. medulla oblongata) are primarily involved in the central regulation of the sympathetic outflow. Spinal sympathetic preganglionic neurons obtain strong excitatory drive from medulla oblongata (especially neurones located in the rostral ventrolateral medulla (RVLM), which is also a vasomotor center). This excitatory flow from the RVLM may be attributable to excitatory inputs from other supramedullary regions of the CNS (e.g. pons, hypothalamus, and amygdala) (Dampney 1994, Fisher et al. 2009). We assume that MVP may have dysregulation at the subcortical level, which results in an increase of sympathetic input, especially into cardiovascular system. This hypothesis of sympathetic overactivity can be sustained by hyperadrenergic state, represented by findings of increased plasma and urine epinephrine/norepinephrine in MVP patients (da Silva et al. 2007). Additionally, Beketova et al. (2018) referred severe vasomotor disturbances in adolescents with MVP, which may indicate hyperresponsiveness of blood vessels due to excessive autonomic responsiveness.

Moreover, previous studies reported that movement of the mitral valves is not entirely passive. There is a rising possibility, that these leaflets are neurally controlled tissue. Experimental studies of mitral valves show rich innervation with postganglionic autonomic nerves patterns (Williams and Jew 2004, Itoh et al. 2009). Additionally, presence of sympathetic and parasympathetic nerves was reported along the subendocardial site on the atrial aspect of the human mitral valve (Oki et al. 1995). Mentioned part of the mitral valve represents the most susceptible area to mechanical stimuli due to MVP. Thus, mechanical stimuli from this area may be transmitted to the CNS via afferent sensory nerves which are also present in mitral valve. Han et al. (2000) suggested that an inappropriate circuit between the central and peripheral nerves in the mitral valves may be responsible for the autonomic dysfunction in MVP and subsequently could later lead to the cardiovascular complications associated with this diagnosis.

Further, the psychopathological states such as anxiety associated with emotional dysregulation could be related to sympathetic abnormal regulation in MVP. For example, anxiety and mood disorders have high prevalence among young individuals with MVP (Lung et al. 2008). According to neurovisceral integration model (Thayer and Lane 2000), the CAN represents also complex system coordinating the attentional and emotional/affective functioning, with respect to the modulation of the autonomic responses. More specifically, emotional regulation is conditioned by effective functioning of prefrontal-subcortical inhibitory 
circuits (Thayer and Lane 2000). In physiological state the prefrontal cortex has inhibitory impact over sympathoexcitatory subcortical circuits resulting in high cardiac vagal control. Reversely, diminished prefrontal activity is associated with disruption of its inhibitory functioning leading to dominance of sympathoexcitatory subcortical circuits (Park and Thayer 2014). Moreover, amygdala is one of the most consistently identified subcortical regions of hyperactivity in anxiety (Holzschneider and Mulert 2011). Thus, disruption of prefrontal cortex inhibitory control linked to emotional dysregulation could represent an important pathomechanism leading to increased cardiovascularsympathetic activity associated with decreased cardiovagal control in MVP (Bona Olexova et al. 2020). This is also in accordance with neurovisceral integration model which interconnect increased sympathetic nervous activity with anxiety disorders (Thayer and Lane 2000). Taken together, altered inhibitory control of prefrontal cortex associated with hyperactive flow from vasomotor center can together lead to increased sympathetic activity in young MVP patients.

From a developmental aspect, physiological maturation of the cardiac ANS in healthy children and adolescents aged 0.5 to 20 years performs as follows: the cardiac parasympathetic activity followed an exponential increase from infancy associated with a plateau phase during middle childhood, followed by a slight decrease to adolescence, the cardiac sympathetic activity showed a more linear trend, with a gradual decrease from infancy to adolescence (Harteveld et al. 2021). In this aspect, a recent study assumed that insufficient maturation of cardiovagal regulation during adolescence can be associated with development of psychopathology and other diseases (Koenig 2020). Therefore, we suggest that adolescents with MVP has altered vagal maturation during growing up, comparing to their healthy peers, resulting in predominance of resting sympathetic cardiovascular activity, as we revealed in our study. It is questionable whether altered MVP-linked sympathetic cardiovascular dysregulation reflects only abnormalities in the central autonomic regulatory network or it is more associated with MVP-linked psychophysiological/developmental characteristics. Further research to elucidate this important question is needed.

\section{Limitations of the study}

The findings of this study need to be validated in a larger sample with respect to gender. Moreover, the cardiovascular control was assessed only in the rest phase, thus, the autonomic response to other physiological, emotional, cognitive or social stressors might bring more information about autonomic regulatory mechanisms in MVP.

\section{Conclusions}

This study revealed sympathetically-mediated cardiovascular overactivity in adolescent MVP evaluated by using non-invasive complex assessment of the conceivable markers of sympathetic vasomotor and cardiac chronotropic regulation. Further studies are needed to elucidate pathways linking MVP and sympathetic dysregulation as a potential pathomechanism leading to higher cardiovascular risk in adolescent patients suffering from MVP.

\section{Conflict of Interest}

There is no conflict of interest.

\section{Acknowledgements}

This work was funded by the Slovak Scientific Grant Agency under grants VEGA 1/0030/22 and VEGA 1/0190/20, grants UK/80/2021 and UK/63/2021.

\section{References}

BEKETOVA GV, SOLDATOVA OV, GAN RV, HORIACHEVA IP, ALEKSIEIENKO NV, NEKHAIENKO MI, ZBORSHCHIK MV: Daily profile of blood pressure in adolescents with mitral valve prolapse. World Med Biol 14: 9-12, 2018. https://doi.org/10.26724/2079-8334-2018-3-65-9-12

BENARROCH EE: The central autonomic network: functional organization, dysfunction, and perspective. Mayo Clin Proc 68: 988-1001, 1993. https://doi.org/10.1016/S0025-6196(12)62272-1

BERNTSON GG, QUIGLEY KS, NORMAN GJ, LOZANO D: Cardiovascular psychophysiology. In: Handbook of Psychophysiology. CACIOPPO JT, TASSINARY LG, BERNTSON GG (eds), Cambridge University Press, Cambridge, 2016, pp 183-216. 
BIERING-SØRENSEN T, QUEREJETA ROCA G, HEGDE SM, SHAH AM, CLAGGETT B, MOSLEY TH, BUTLER KR, SOLOMON SD: Left ventricular ejection time is an independent predictor of incident heart failure in a community-based cohort. Eur J Heart Fail 20: 1106-1114, 2018. https://doi.org/10.1002/ejhf.928

BILOVOL O, KNIAZKOVA I, MARYNA B, MISHCHENKO V, TSIHANKOV O, MAZII V: Magnesium in idiopathic mitral valve prolapse. Serbian J Exp Clin Res 21: 351-359, 2019. https://doi.org/10.2478/sjecr-2019-0026

BONA OLEXOVA L, SEKANINOVA N, JURKO A, VISNOVCOVA Z, GRENDAR M, JURKO T, TONHAJZEROVA I: Respiratory sinus arrhythmia as an index of cardiac vagal control in mitral valve prolapse. Physiol Res 69: 163-169, 2020. https://doi.org/10.33549/physiolres. 934402

BOUDOULAS KD, BOUDOULAS H: Floppy mitral valve (FMV)/mitral valve prolapse (MVP) and the FMV/MVP syndrome: Pathophysiologic mechanisms and pathogenesis of symptoms. Cardiology 126: 69-80, 2013. https://doi.org/10.1159/000351094

BOUDOULAS KD, PITSIS AA, BOUDOULAS H: Floppy mitral valve (FMV) - mitral valve prolapse (MVP) - mitral valvular regurgitation and FMV/MVP syndrome. Hell J Cardiol 57: 73-85, 2016. https://doi.org/10.1016/j.hjc.2016.03.001

BOUDOULAS KD, PITSIS AA, MAZZAFERRI EL, GUMINA RJ, TRIPOSKIADIS F, BOUDOULAS H: Floppy mitral valve/mitral valve prolapse: A complex entity with multiple genotypes and phenotypes. Prog Cardiovasc Dis 63: 308-326, 2020. https://doi.org/10.1016/j.pcad.2020.03.004

CHANG CJ, CHEN YC, LEE CH, YANG IF, YANG TF: Posture and gender differentially affect heart rate variability of symptomatic mitral valve prolapse and normal adults. Acta Cardiol Sin 32: 467-476, 2016. https://doi.org/10.6515/acs20150728b

CORÎCI OM, TĂNASIE CA, ALEXANDRU DO, FLORESCU MC, COMĂNESCU MV, KAMAL KC, ŢENEA-COJAN TŞ, IANCĂU M, DINESCU SN: A morpho-functional study using PEP/LVET ratio and global longitudinal strain in patients with dilated cardiomyopathy. Rom J Morphol Emryol 59: 93-103, 2018.

DA SILVA EP, PEDRO MM, VARELA MG, CORTEZ-DIAS N, BICHO MP, MADEIRA HC, LOPES MG: Heart rate and blood pressure in mitral valve prolapse patients: Divergent effects of long-term propranolol therapy and correlations with catecholamines. Anadolu Kardiyol Derg 7 (Suppl 1): 107-109, 2007.

DAMPNEY R A: Functional organization of central pathways regulating the cardiovascular system. Physiol Rev 74: 323-364, 1994. https://doi.org/10.1152/physrev.1994.74.2.323

DAWSON ME, SCHELL AM, FILION DL: The electrodermal system. In: Handbook of Psychophysiology. CACIOPPO JT, TASSINARY LG, BERNTSON GG (eds), Cambridge University Press, Cambridge, USA, 2000, pp 200-223.

DAWSON ME, SCHELL AM, FILION DL: The electrodermal system. In: Handbook of Psychophysiology. CACIOPPO JT, TASSINARY LG, BERNTSON GG (eds), Cambridge University Press, New York, USA, 2007, pp 159-181.

DELLING FN, GONA P, LARSON MG, LEHMAN B, MANNING WJ, LEVINE RA, BENJAMIN EJ, VASAN RS: Early expression of mitral valve prolapse in the framingham offspring: phenotypic spectrum. J Am Soc Echocardiogr 27: 17-23, 2014. https://doi.org/10.1016/j.echo.2013.09.015

FIGNER B, MURPHY RO: Using skin conductance in judgment and decision making research. In: $A$ Handbook of Process Tracing Methods for Decision Research. SCHUTLE-MECKLENBECK M, KUEHBERGER A, RANYARD R (eds), Psychology Press, New York, 2010, pp 163-184.

FISHER JP, YOUNG CN, FADEL PJ: Central sympathetic overactivity: Maladies and mechanisms. Auton Neurosci Basic Clin 148: 5-15, 2009. https://doi.org/10.1016/j.autneu.2009.02.003

GARRIDO A, DUSCHEK S, RODRÍGUEZ ÁRBOL J, GONZÁLEZ USERA I, VILA J, MATA JL: Sympathetic contributions to habituation and recovery of the cardiac defense response. Biol Psychol 151: 107846, 2020. https://doi.org/10.1016/j.biopsycho.2020.107846

GOLDSTEIN DS, BENTHO O, PARK MY, SHARABI Y: Low-frequency power of heart rate variability is not a measure of cardiac sympathetic tone but may be a measure of modulation of cardiac autonomic outflows by baroreflexes. Exp Physiol 96: 1255-1261, 2011. https://doi.org/10.1113/expphysiol.2010.056259 
GRILLETTI JVF, SCAPINI KB, BERNARDES N, SPADARI J, BIGONGIARI A, MAZUCHI F DE AES, CAPERUTO EC, SANCHES IC, RODRIGUES B, DE ANGELIS K: Impaired baroreflex sensitivity and increased systolic blood pressure variability in chronic post-ischemic stroke. Clinics 73: e253, 2018. https://doi.org/10.6061/clinics/2018/e253

HAN L, HO TF, YIP WC, CHAN KY: Heart rate variability of adolescents with mitral valve prolapse. J Electrocardiol 33: 219-224, 2000. https://doi.org/10.1054/jelc.2000.7661

HARTEVELD LM, NEDEREND I, TEN HARKEL ADJ, SCHUTTE NM, DE ROOIJ SR, VRIJKOTTE TGM, OLDENHOF H, POPMA A, JANSEN LMC, SUURLAND J, SWAAB H, DE GEUS EJC: Maturation of the cardiac autonomic nervous system activity in adolescents and adolescents. J Am Heart Assoc 10: e017405, 2021. https://doi.org/10.1161/JAHA.120.017405

HOLZSCHNEIDER K, MULERT C: Neuroimaging in anxiety disorders. Dialogues Clin Neurosci 13: 453-461, 2011. https://doi.org/10.31887/DCNS.2011.13.4/kholzschneider

HILL LK, HU DD, WILLIAMS DP, SOFLETEA G, COCHRAN J, SOLLERS JJ, THAYER JF: Effects of autonomic innervation on the heart as a function of effector tissue. Biomed Sci Instrum 46: 202-207, 2010.

ITOH A, KRISHNAMURTHY G, SWANSON JC, ENNIS DB, BOTHE W, KUHL E, KARLSSON M, DAVIS LR, MILLER DC, INGELS NB: Active stiffening of mitral valve leaflets in the beating heart. Am J Physiol Heart Circ Physiol 296: H1766-H1773, 2009. https://doi.org/10.1152/ajpheart.00120.2009

JIRA M, ZAVODNA E, NOVAKOVA Z, FISER B, HONZIKOVA N: Reproducibility of blood pressure and inter-beat interval variability in man. Physiol Res 59: 113-121, 2010. https://doi.org/10.33549/physiolres. 932002

KOENIG J: Neurovisceral regulatory circuits of affective resilience in youth. Psychophysiology 57: e13568, 2020. https://doi.org/10.1111/psyp.13568

LUNG FW, CHENG CT, CHANG WT, SHU BC: Anxiety and mood disorder in young males with mitral valve prolapse. J Multidiscip Healthc 1: 89-92, 2008. https://doi.org/10.2147/JMDH.S4264

MESTANIK M, MESTANIKOVA A, VISNOVCOVA Z, CALKOVSKA A, TONHAJZEROVA I: Cardiovascular sympathetic arousal in response to different mental stressors. Physiol Res 64: 585-594, 2015. https://doi.org/10.33549/physiolres.933217

MILLER MA, DUKKIPATI SR, TURAGAM M, LIAO SL, ADAMS DH, REDDY VY: Arrhythmic mitral valve prolapse: JACC review topic of the week. J Am Coll Cardiol 72: 2904-2914, 2018. https://doi.org/10.1016/j.jacc.2018.09.048

OKI T, FUKUDA N, KAWANO T, IUCHI A, TABATA T, MANABE K, KAGEJI Y, SASAKI M, YAMADA H, ITO S: Histopathologic studies of innervation of normal and prolapsed human mitral valves. J Heart Valve Dis 4: 496-502, 1995.

PARK G, THAYER JF: From the heart to the mind: cardiac vagal tone modulates top-down and bottom-up visual perception and attention to emotional stimuli. Front Psychol 5: 278, 2014. https://doi.org/10.3389/fpsyg.2014.00278

PORTA A, TOBALDINI E, GUZZETTI S, FURLAN R, MONTANO N, GNECCHI-RUSCONE T: Assessment of cardiac autonomic modulation during graded head-up tilt by symbolic analysis of heart rate variability. Am J Physiol Heart Circ Physiol 293: H702-H708, 2007. https://doi.org/10.1152/ajpheart.00006.2007

POSADA-QUINTERO HF, FLORIAN JP, ORJUELA-CAÑÓN AD, ALJAMA-CORRALES T, CHARLESTONVILLALOBOS S, CHON KH: Power spectral density analysis of electrodermal activity for sympathetic function assessment. Ann Biomed Eng 44: 3124-3135, 2016. https://doi.org/10.1007/s10439-016-1606-6

SHAFFER F, GINSBERG JP: An overview of heart rate variability metrics and norms. Front Public Health 5: 258, 2017. https://doi.org/10.3389/fpubh.2017.00258

SHAH PM: Current concepts in mitral valve prolapse-diagnosis and management. J Cardiol 56: 125-133, 2010. https://doi.org/10.1016/j.jjcc.2010.06.004

SHAH SN, GANGWANI MK, OLIVER TI: Mitral Valve Prolapse. In: StatPearls [Internet]. Treasure Island (FL): StatPearls Publishing; 2020.

SILVA LEV, GERALDINI VR, DE OLIVEIRA BP, SILVA CAA, PORTA A, FAZAN R: Comparison between spectral analysis and symbolic dynamics for heart rate variability analysis in the rat. Sci Rep 7: 1-8, 2017. https://doi.org/10.1038/s41598-017-08888-w 
STAUSS HM: Identification of blood pressure control mechanisms by power spectral analysis. Clin Exp Pharmacol Physiol 34: 362-368, 2007. https://doi.org/10.1111/j.1440-1681.2007.04588.x

TAVAKOLIAN K: Systolic time intervals and new measurement methods. Cardiovasc Eng Technol 7: 118-125, 2016. https://doi.org/10.1007/s13239-016-0262-1

THAYER JF, LANE RD: A model of neurovisceral integration in emotion regulation and dysregulation. J Affect Disord 61: 201-216, 2000. https://doi.org/10.1016/S0165-0327(00)00338-4

THEOFILOGIANNAKOS EK, BOUDOULAS KD, GAWRONSKI BE, LANGAEE TY, DARDAS PS, NINIOS V, KELPIS TG, JOHNSON JA, PITSIS AA, BOUDOULAS H: Floppy mitral valve/mitral valve prolapse syndrome: Beta-adrenergic receptor polymorphism may contribute to the pathogenesis of symptoms. J Cardiol 65: 434-438, 2015. https://doi.org/10.1016/j.jjcc.2014.07.020

TONHAJZEROVA I, FARSKY I, MESTANIK M, VISNOVCOVA Z, MESTANIKOVA A, HRTANEK I, ONDREJKA I: Symbolic dynamics of heart rate variability - A promising tool to investigate cardiac sympathovagal control in attention deficit/hyperactivity disorder (ADHD)? Can J Physiol Pharmacol 94: 579-587, 2016. https://doi.org/10.1139/cjpp-2015-0375

VENABLES PH, GARTSHORE SA, O'RIORDAN PW: The function of skin conductance response recovery and rise time. Biol Psychol 10: 1-6, 1980. https://doi.org/10.1016/0301-0511(80)90002-2

VISNOVCOVA Z, MESTANIK M, JAVORKA M, MOKRA D, GALA M, JURKO A, CALKOVSKA A, TONHAJZEROVA I: Complexity and time asymmetry of heart rate variability are altered in acute mental stress. Physiol Meas 35: 1319-1334, 2014. https://doi.org/10.1088/0967-3334/35/7/1319

WILLIAMS TH, JEW JY: Is the mitral valve passive flap theory overstated? An active valve is hypothesized. Med Hypotheses 62: 605-611, 2004. https://doi.org/10.1016/j.mehy.2003.12.001

ZHANG R, IWASAKI K, ZUCKERMAN JH, BEHBEHANI K, CRANDALL CG, LEVINE BD: Mechanism of blood pressure and R-R variability: insights from ganglion blockade in humans. J Physiol 543: 337-348, 2002. https://doi.org/10.1113/jphysiol.2001.013398 